\title{
KARAKTERISTIK USAHATANI CABAI RAWIT DI DUSUN TANGGULUN DESA LAMONGAN KECAMATAN ARJASA KABUPATEN SITUBONDO
}

\author{
Andi Wirawan Setiady ${ }^{1}$, Bambang Suyadi ${ }^{1}$, Titin Kartini ${ }^{1}$ \\ ${ }^{1}$ Program Studi Pendidikan Ekonomi, Fakultas Keguruan dan Ilmu Pendidikan, Universitas Jember
}

\begin{abstract}
This study aims to examine more deeply about the characteristics of chili farming system in Dusun Tanggulun Lamongan Village Arjasa District Situbondo Regency in the management of land, capital, and labor. Type of research used in this research is descriptive with qualitative approach. Determination of research location determined by Purposive Area method, that is done intentionally by researcher, that is in Dusun Tanggulun Desa Lamongan Arjasa Sub-District Situbondo Regency. The main informants in this study were 5 chili pepper farmers and 9 supporting informants were 5 wives from main informants and 4 farm laborers. Data collection methods used by researchers include interview methods, observation methods, and document methods. Data analysis used in this research consists of several stages, namely data reduction phase, data presentation stage and conclusion drawing stage. The results showed that the chili farmers use the land in the cayenne pepper farm with a semicircular shape that extends or called the becovered by plastic mulch. Majority of the main informants use land in the form of beds with mulch plastic covered, the capital is used to buy manure, Urea, ZA, TSP, KCI, Leaf fertilizer, Lime, Plastic mulch, Polibag, Bamboo, Pesticide, and pay land-making farm workers, Pickers of cayenne pepper, as well as using labor from within the family and from outside the family.
\end{abstract}

Keywords: Characteristics Farm, cayenne pepper, Land, Capital, Labor

\section{PENDAHULUAN}

Pertanian merupakan sektor primer dalam perekonomian Indonesia. Artinya pertanian merupakan sektor utama yang menyumbang hampir dari setengah perekonomian. Pertanian juga memiliki peran nyata sebagai penghasil devisa negara melalui ekspor. Maka dari sektor pertaniaan mendapat perhatian yang cukup besar dari pemerintah karena sangat penting dalam rangka pembanguanan ekonomi jangka panjang maupun dalam rangka pemulihan ekonomi bangsa. Selain itu sektor pertanian juga dapat menjadi basis dalam pengembangan usaha berbasis pertanian.

Menurut Prof. Bachtiar Rivai (dalam Hernanto,1996:7) mendefinisikan usahatani sebagai organisasi dari alam, kerja, dan modal yang ditujukan kepada produksi di lapangan pertanian. Organisasi ini ketatalaksanaannya berdiri sendiri dan sengaja diusahakan oleh sesorang atau sekumpulan orang, segolongan sosial, baik yang terkait genologis, politis maupun teritorial sebagai pengelolanya.

Di Dusun Tanggulun Desa Lamongan Kecamatan Arjasa Kabupaten Situbondo mayoritas penduduknya berusahatani cabai rawit, dalam berusahatani cabai rawit para petani melakukann pengelolahan sumber daya lahan, modal, dan tenaga kerja di lahan tersebut para petani hanya menanam cabai rawit, meraka menjadikan cabai rawit sebagai tanaman utama di lahan pertanian mereka, dalam menjalankan usahataninya para petani cabai rawit di dusun tersebut tidak melakukannya sendiri melainkan dibantu oleh keluarganya dan para buruh tani.

Penggunaan lahan dalam usahatani cabai rawit, itu tergantung dari apa yang ditentukan oleh petani cabai rawit. pengelolahan yang baik dan benar akan membuat Usahatani cabai rawit dijalankan oleh petani di Dusun Tanggulun akan sesuai dengan yang diharapkan, lahan yang di garap oleh petani cabai rawit itu biasanya berbeda dengan usahatani lainnya, dalam usahatani cabai rawit bentuk lahan yang diguanakan itu bermacam-macam, ada yang menggunakan lahan 
polibag, lahan sawah dan yang lainnya, sedangkan bentuk lahan yang digunakan itu juga bermacam-macam tergantung apa yang telah diputuskan oleh petani dan pengetahuan yang dimilki oleh petani cabai rawit. Namun semakin berkurangnya lahan pertanian, maka bisa membawa dampak yang besar terhadap perekonomian mereka, mereka harus rela menyisihkan keuntungannya untuk membayar sewa lahan yang biasanya ikut naik apabila keuntungan mereka naik. sedangkan bagi buruh tani ketidaktersedian lahan merupakan bencana hilangnya mata pencaharian mereka.

Bagi usah atani cabai rawit di Dusun Tanggulun Desa Lamongan Modal merupkan hal yang sangat penting dalam menjalankan usaha taninya, namun petani di dusun tersebut dalam pembentukan modal sering dilakukan dengan cara menabung dengan menyisihkan pendapatannya, penggunaan modal yang tepat akan membuat, modal yang digunakan oleh petani dalam usahataninya akan menjadi efektif, pemilihan pupuk, obat-obatan dan keputusankeputusan yang lainya yang yang di gunakan oleh petani. Namun kuranngnya penyuluhan dan bantuan dari pemerintah membuat usahatani cabai rawit yang mereka jalankan menjadi sulit untuk berkembang.

Tenaga kerja dalam usahatani cabai rawit merupakan hal yang sangat penting, karena dalam usahatani cabai rawit tidak dapat di kerjakan sendiri oleh petani. Ketersediaan tenaga kerja yang dimiliki dalam usahatani akan sangat berpengaruh terhadap kegiatan usahatani cabai rawit di Dusun Tanggulung. Dalam menjalankan usahatani biasanya para petani tidak melakukanya sendiri melainkan dibantuh oleh keluarganya dan buruh tani untuk bekerja di lahan pertanian mereka, setelah itu buruh tani tersebut mendapatkan upah. Keberadaan tenaga kerja (buruh tani) akan banyak membantu pekerjaan petani yang tidak dapat dikerjakan sendiri seperti mengolah lahan, dan memetik cabai rawit, namun dalam memilih tenaga kerja para petani harus memperhatikan kualitas yang di miliki oleh setiap tenaga kerja yang bekerja dalan lahan pertaniannya, dalam usahatani tenaga kerja jenis kelamin pria lebih dibutuhkan sebagai pengolah lahan pertanian.

Karakteristik adalah ciri khas seseorang dalam meyakini, bertindak ataupun merasakan. Berbagai teori pemikiran dari karakteristik tumbuh untuk menjelaskan berbagai kunci karakteristik manusia. Karakteristik adalah fitur pembeda dari seseorang atau sesuatu. Karakteristik didefinisikan sebagai kualitas atau sifat. Contoh dari karakteristik adalah kecerdasan. (Boeree, 2008:426).

Sedangkan menurut Prof. Bachtiar Rivai (dalam Hernanto,1996:7) mendefinisikan usahatani sebagai organisasi dari alam, kerja, dan modal yang ditujukan kepada produksi di lapangan pertanian. Organisasi ini ketatalaksanaannya berdiri sendiri dan sengaja diusahakan oleh sesorang atau sekumpulan orang, segolongan sosial, baik yang terkait genologis, politis maupun teritorial sebagai pengelolanya.

Berdasarkan penjelasan di atas, maka dapat ditarik kesimpulan bahwa karakteristik usahatani merupakan ciri-ciri khusus atau sifat khas dari segala bentuk pengorganisasian dan pengolahan sumber daya dari alam, kerja, dan modal yang dimiliki petani agar berjalan secara efisien dan kosisten, dengan tujuan untuk menambah kesejahteraan dan memperbaiki taraf kehidupan petani. Terkait dengan karakteristik usahatani cabai raiwit di Dusun Tanggulun Desa Lamongan Kecamatan Arjasa Kabupaten Situbondo, akan dilakukan penelitian mendeskripsikan ciri-ciri khusus dari segala bentuk pengorganisasian dan pengolahan sumber 
daya dari alam, kerja, dan modal yang dimiliki petani cabai rawit di Dusun Tanggulun Desa Lamongan agar berjalan secara efisien dan kosisten, dengan tujuan untuk menambah kesejahteraan dan memperbaiki taraf kehidupan petani.

Berdasarkan latar belakang di atas, maka peneliti melakukan penelitian dengan judul karakteristik usahatani cabai rawit di Dusun Tanggulun Desa Lamongan Kecamatan Arjasa Kabupaten Situbondo.

\section{METODE PENELITIAN}

Penelitian ini merupakan penelitian deskriptif dengan pendekatan kualitatif. Untuk mendeskripsikan tentang karakteristik usahatani cabai rawit yang ada di Dusun Tanggulun Desa Lamongan Kecamatan Arjasa Kabupaten Situbondo. Penentuan lokasi penelitian ditentukan dengan metode Purposive Area, yaitu di Dusun Tanggulun Desa Lamongan Kecamatan Arjasa Kabupaten Situbondo, karena di Desa Lamongan khususnya Dusun Tanggulun Di Dusun Tanggulun Desa Lamongan Kecamatan Arjasa Kabupaten Situbondo, mayoritas penduduknya berusahatani cabai rawit, dalam berusahatani cabai rawit para petani, meraka menjadikan cabai rawit sebagai tanaman utama di lahan pertanian mereka.

Sumber data dalam penelitian ini meliputi sumber data yang diperoleh dari 5 petani cabai rawit informan utama dan 9 informan pendukung. Informan utama dalam penelitian ini adalah petani di Dusun Tanggulun Desa Lamongan Kecamatan Arjasa Kabupaten Situbondo yang mengkhususkan berusahatani cabai rawit di dalam lahan pertaniannya dan telah berusahatani cabai rawit minimal 3 tahun. Sedangkan informan pendukung dalam penelitian ini adalah istri petani cabai rawit dan buruh tani di Dusun Tanggulun Desa Lamongan Kecamatan Arjasa Kabupaten Situbondo. Metode pengumpulan data yang digunakan terdiri dari wawancara, observasi dan dokumen. Analisis data yang digunakan adalah reduksi data, penyajian data, dan penarikan kesimpulan.

\section{HASIL DAN PEMBAHASAN}

\section{Hasil Penelitian}

Data utama yang dikumpulkan merupakan data yang diperoleh dari hasil observasi dan wawancara yang dilakukan oleh peneliti terhadap subyek penelitian yaitu petani cabai rawit di Dusun Tanggulun Desa Lamongan Kecamatan Arjasa Kabupaten Situbondo. Adapun karakteristik usahatani cabai rawit yang ada di Dusun Tanggulun Desa Lamongan Kecamatan Arjasa Kabupaten Situbondo

\section{Bentuk Lahan}

Bentuk lahan dalam usahatani cabai rawit itu berbeda dengan usahatani yang lainnya. Dalam usahatani cabai rawit, lahan sebelum digunakan diolah terlebih dahulu. Pengolahan lahan yang dilakukan oleh petani dimulai dengan membersihkan sampah, plastik mulsa dan sisa-sisa tanaman pada periode tanam sebelumnya. Kemudian untuk ngembalikan kondisi kesuburan tanah agar tetap gembur, petani mengolah menggunakan cangkul, Setelah lahan dicangkul menjadi gembur kemudian lahan yang dibentuk bedengan dan dipasang plastik mulsa.

Bentuk lahan yang digunakan oleh 5 informan utama yaitu bapak E, bapak R, bapak S, bapak T, dan bapak N, dalam usahatani cabai rawit di Dusun Tanggulun Desa Lamongan untuk 
menanam tanaman cabai rawit yaitu lahan yang berbentuk setengah lingkangkaran yang memanjang atau disebut bedengan dengan dipasangi plastik mulsa, itu merupakan ciri-ciri khusus bentuk lahan yang digunakan oleh petani cabai rawit di Dusun Tanggulun Desa Lamongan Kecamatan Arjasa.

\section{Penggunaan Modal}

Modal merupakan unsur pembentuk usahatani cabai rawit yang sangat penting dalam keberhasilan usahatani cabai rawit. Namun untuk mengembangkan usahatani yang dijalankannya para petani harus pintar-pintar dalam mengelolah modal yang dimilikinya yaitu dengan memilih apa yang tepat untuk usahatani cabai rawitnya, seperti apa yang terjadi di dalam usahatani cabai rawit di Dusun Tanggulun Desa Lamongan. Berikut ini pengelolaan modal yang diguanakan oleh petani dalam usahatani cabai rawit di Dusun Tanggulun Desa Lamongan Kecamtan arjasa Kabupaten Situbondo.

Pengelolaan modal yang dilakukan oleh petani cabai rawit memiliki cara tersendiri tergantung dari pengetahuan dan luas lahan, namun dari bentuk bahan yang yang digunakan, mayoritas petani menggunakan bahan yang sama. Seperti yang dilakukan oleh bapak E, bapak $\mathrm{S}$, bapak $\mathrm{T}$, bapak $\mathrm{N}$, mereka menggunakan modal yang dimilikinya untuk membayar buruh tani laki-laki, dimana buruh tani laki-laki tersebut membantu beliau dalam mengolah lahan pertanian seperti membuat bedengan, memasang plastik mulsa hingga memasang bambu. Setelah itu para petani tersebut menggunakan modalnya untuk membeli kapur untuk dicampur dengan tanah di bedengan, selain itu juga dibelikan pupuk kandang juga untuk di campurkan dengan tanah di bedengan, plastik mulsa digunakan untuk menutupi bedengan, kemudian modalnya dibelikan pupuk Urea, pupuk ZA, TSP, KCI, , bambu 3 batang di buat kecil kecil untuk menahan batang tanaman agar tidak mudah patah karena tehempas angin, pestisida dan buruh tani pemetik buah cabai rawit yang digunakan ketika sudah waktunya memetik cabai rawit. Namun 1 informan utama yaitu bapak R, pengelolaan modalnya berbeda dengan yang lainnya, yaitu beliau menngunakan modalnya untuk membeli bibit cabe rawit, pupuk kandang, kapur, Urea, SP, Korkali, plastik mulsa, bambu, pestisida, buruh tani pembuatan lahan, penanam bibit cabai rawit, pemetik cabai rawit, sewa lahan, alat-alat pertanian.

\section{Penggunaan Tenaga Kerja}

Tenaga kerja dalam usahatani cabai rawit di Dusun Tanggulun Desa Lamongan memang sangat memtukan dalam usahatani, Dalam penentuan penggunaan tenaga kerja oleh petani merupakan keputusan petani dalam menentukannya, baik itu tenaga kerja yang berasal dari keluarga maupun tenaga kerja dari luar keluarga. Banyaknya tenaga kerja diguanakan perlu disesuaikan dengan kebutuhan sampai tingkat tertentu sehingga jumlahnya optimal.

Penggunaan tenaga kerja dalam usahatani cabai rawit di Dusun Tanggulun Desa Lamongan yang digunakan oleh 5 informan utama semuanya sama, yaitu bapak E, bapak R, bapak $\mathrm{S}$, bapak $\mathrm{T}$, dan bapak $\mathrm{N}$, tenaga kerja yang digunakan adalah berasal dari dalam keluarga seperti istri, anak, buruh tani. Istri pak Edi dalam usahataninya membantu menanam, membersihkan tanaman penggaggu tanaman cabai rawit, menyiram tanaman cabai rawit, memetik buah cabai rawit, serta mengantarkan makanan ke lahan pertanian. Serta di bantu oleh tenaga kerja dari luar keluarga seperti buruh tani laki-laki dan buruh tani perempuan, buruh tani laki-laki melakukan pekerjaan mengolah sawah seperti membuat bedengan, membuat 
pematang sawah dan memasang plastik mulsa, dan buruh tani perempuan melakukan pekerjaan memetik buah cabai rawit.

\section{Pembahasan}

Berdasarkan hasil penelitian yang dilakukan oleh peneliti menggunakan data yang diperoleh dari petani cabai rawit menunjukan bahwa karakteristik usahatani cabai rawit dapat di lihat dari bentuk lahan, penggunaan modal dan penggunaan tenaga kerja.

Hasil penelitian menunjukan bahwa bentuk lahan yang di gunakan oleh petani dalam usahatani cabai rawit di Dusun Tanggulun Desa Lamongan mayoritas berbentuk setengah lingkaran yang memanjang atau disebut dengan bedengan dalam membuat bedengan petani menggungakan cangkul. Lahan dicangkul hingga menjadi gembur. Kemudian setelah itu lahan di bentuk bedengan. Setelah bedengan sudah jadi maka langkah selanjutnya petani akan menutupi bedengan dengan plastik mulsa. Sehingga bentuk lahan yang diguanakan oleh petani cabai rawit dalam usahatani cabai rawitnya yaitu berbentuk bedengan dengan ditutupi plastik mulsa. Hal tersebut sesuai dengan pernyataan Abdjad dkk (2011:24) bahwa dalam usahatani cabai rawit cara pembuatan bedengan dilakukan bertahap. Tahap pertama dikerjakan pada waktu penghancuran bongkah bongkah tanah. Tahap kedua dikerjakan secara khusus dengan bentuk dan ukuran standar. Permukaan bedeng dibentuk menyerupai bentuk setengah lingkaran dan diratakan. Maksudnya agar plastik mulsa dapat di pasang dengan mudah dan melekat erat.

Pengggunaan modal dalam usahatani cabai rawit di Dusun Tanggulun Desa Lamongan, menunjukan bahwa modal digunakan oleh petani untuk membeli Pupuk kandang, Urea, ZA, TSP, KCI, Pupuk daun, Kapur, Plastik mulsa, Polibag, Bambu, Pestisida, dan membayar Buruh tani pembuatan lahan, Pemetik cabai rawit. Dari 5 informan penelitian 4 diantaranya pengelolahan modalnya digunakan untuk hal yang sama. Sehingga mayoritas petani cabai rawit di Dusun Tanggulun Desa Lamongan pengelolaan modalnya digunakan untuk membeli Pupuk kandang, Urea, ZA, TSP, KCI, Pupuk daun, Kapur, Plastik mulsa, Polibag, Bambu, Pestisida, dan membayar Buruh tani pembuatan lahan, pemetik cabai rawit. Hal tersebut sesuai dengan pernyataan abdjad dkk (2001:26) bahwa setelah pupuk kandang dan kapur ditebar secepatnya pemupukan bedeng ditutup mulsa plastik. Plastik dipersiapkan sebelumnya agar setelah selesai penebaran pupuk, dapat segera dilakukan pemasangan mulsa. cara pemasangan mulsa cukup mudah hanya saja letaknya jangan sampai terbalik. Waktu pemasangan sebaiknya siang hari pada saat temperatur udara tinggi. maksudnya agar plastik dapat dapat dipancang sehingga melekat erat dengan permukaan bedeng. Mulsa plastik yang sudah tertup sempurna kemudian dijepit dengan belahan bambu.

Tenaga kerja yang digunakan dalam usahatani cabai rawit dibagi menjadi dua yaitu tenaga kerja dari dalam keluarga dan tenaga kerja dari luar keluarga. Pada usahatani cabai rawit di Dusun Tanggulun Desa Lamongan tenaga kerja yang digunakan berasal dari dalam keluarga, seperti petani cabai rawit sendiri, istri petani cabai rawit, dan anak-anaknya, dan ditambah dengan tenaga kerja dari luar keluarga seperti buruh tani. Hal tersebut juga diungkapakan oleh Moehar (2004:85) Berbicara tenaga kerja di Indonesia dan juga sebagian besar negara-negara berkembang pada mulanya merupakan tenaga yang dicurahkan untuk usahatani sendiri atau usahatani keluarga. Keadaan ini berkembang dengan semakin meningkatnya kebutuhan manusia dan semakin majunya usaha pertanian, sehingga dibutuhkan tenaga dari luar keluarga. 


\section{KESIMPULAN DAN SARAN}

Berdasarkan hasil penelitian dan analisis data mengenai karakteristik usahatani cabai rawit di Dusun Tanggulun Desa Lamongan Kecamatan Arjasa Kabupaten Situbondo, dari segi lahan yang digunakan dalam usahatani cabai rawit, lahan yang digunakan berbentuk setengah lingkaaran yang memanjang atau disebut bedengan dengan ditutupi plastik mulsa.

Dari segi modal karakteristik usahatani cabai rawit di Dusun Tanggulun Desa Lamongan Kecamatan Arjasa Kabupaten Situbondo, pengelolaan modal digunakan untuk membeli pupuk kandang, Urea, ZA, TSP, KCI, Pupuk daun, Kapur, Plastik mulsa, Polibag, Bambu, Pestisida, dan membayar Buruh tani pembuatan lahan, pemetik cabai rawit.

Dari segi tenaga kerja karakteristik usahatani cabai rawit di Dusun Tanggulun Desa Lamongan Kecamatan Arjasa Kabupaten Situbondo, tenaga kerja yang digunakan merupakan tenaga kerja dari dalam keluarga yang terdiri dari petani cabai rawit sendiri, istri petani cabai rawit, anak-anaknya di tambah tenaga kerja dari luar keluarga, yang terdiri dari buruh tani lakilaki sebagai pengolah lahan dan buruht tani perempuan sebagai pemetik cabai rawit.

Berdasarkan kesimpulan dari penelitian ini, maka Sebaiknya pengeolaan lahan di lakukan dengan sebaik mungkin oleh petani cabai rawit agar lahan menjai subur dan terhidar dari hama, sehingga hasil buah cabai rawit lebih melimpah. Modal yang digunkan dalam usahatani cabai rawit di Dusun Tanggulun harus dikelola dengan sebaik mungkin sehingga akan didapatkan hasil yang maksimal.

\section{DAFTAR BACAAN}

Abdjad Dkk. 2011. Hot Beauty. Yogyakarta: Cisuren Pusat Pendidikan.

Boeree. 2008. Berbagai Teori Karakteristik Manusia. Jakarta: Pustaka Budiman

Hernanto. 1996. Ilmu Usahatani. Jakarta: PT. Penebar Swadaya.

Daniel, Moehar, M.S. 2004. Pengantar Ekonomi Pertanian. Jakarta: PT Bumi Aksara. 